\title{
Zeolite-Based Materials for the Catalytic Oxidation of VOCs: A Mini Review
}

\author{
Tianshan Xue * and Li Yang \\ Institute of Atmospheric Environment, Chinese Research Academy of Environmental Sciences, Beijing, China
}

Catalysts for VOCs combustion have been widely studied and zeolite-based materials and have been structured to meet the need of particle use in this field. This review summarized several new trends in zeolite-based catalysts for VOCs catalytic oxidation. Intensive effort has been devoted to the optimization of composition and structure of catalysts, abatement of CVOCs, design of zeolite-based monolithic catalysts and adsorbent/catalyst bifunctional material. The suggestions for further work here presented are put forward based on the collation of recently published papers.

OPEN ACCESS

Edited by:

Benoit Louis,

UMR7515 Institut de Chimie et Procédés pour l'Energie, l'Environnement et la Santé (ICPEES),

France

Reviewed by: Subrahmanyam Challapalli, Indian Institute of Technology Hyderabad, India Cristina Megías-Sayago, Université de Strasbourg, France

${ }^{*}$ Correspondence: Tianshan Xue lynnleslie@foxmail.com

Specialty section: This article was submitted to Inorganic Chemistry, a section of the journal

Frontiers in Chemistry

Received: 01 August 2021 Accepted: 20 September 2021 Published: 04 October 2021

Citation: Xue T and Yang L (2021) Zeolite-Based Materials for the Catalytic Oxidation of VOCs: A Mini Review.

Front. Chem. 9:751581. doi: 10.3389/fchem.2021.751581
Keywords: zeolite, VOCs, catalytic, oxidation, monolithic

\section{INTRODUCTION}

Volatile organic compounds (VOCs) as common precursors for $\mathrm{PM}_{2.5}$ (inhalable particles with diameters that are generally $2.5 \mu \mathrm{m}$ and smaller) and $\mathrm{O}_{3}$ which have been highly concerned by researchers. They are general representatives of organic compounds with boiling points below $250^{\circ} \mathrm{C}$ at $101.325 \mathrm{kPa}$ (He C. et al., 2019). The catalytic oxidation of VOCs is considered an efficient method due to the reduced need for fuel and toxic by-product (Liotta, 2010). In the recent decade, zeolitesbased materials have been widely applied in exhaust purification and greenhouse gas adsorption (Megías-Sayago et al., 2019).

In general, zeolites can be divided into macroporous $(>50 \mathrm{~nm})$, mesoporous $(2-50 \mathrm{~nm})$, and microporous $(<2 \mathrm{~nm})$ zeolites, according to the pore size. These particularities directly determine the absorption and catalytic performance of the specific type of zeolite (Chandak et al., 1997). The kinetic diameter of VOCs molecules is usually less than $1 \mathrm{~nm}$. Only when the pore size is larger than the molecular dynamics size of VOCs, they will then enter the pore canal of zeolite, and will be subjected to pore wall superposition or capillary cohesion. This increases the adsorption capacity, further expanding the catalytic reaction rate (Kim and Ahn, 2012). The large specific surface area and suitable pore structure of zeolite materials can reduce the agglomeration of active components and enhance the mechanical strength of materials. In addition, the large number of acidic sites on the surface of zeolites also triggered certain catalytic activity. These advantages reminded researchers to structure zeolite-based catalysts for VOCs combustion.

At present, there are mainly four mechanisms used to explain the surface adsorption, activation and reaction of reactants and catalysts, namely (i) power-low (P-L) mechanism; (ii) Eley-Rideal (E-R) mechanism; (iii) Langmuir Hinshelwood (L-h) mechanism; and (iv) Mars vankrevelen (MVK) mechanism (Behar et al., 2015). The kinetic model can be established by analyzing the conversion data obtained after varying the concentration of VOCs and oxygen in the reaction temperature. The reaction rates of VOCs under different reaction conditions were calculated according to the experimental data, and fitted with different models. The closer the coefficient of determination $\mathrm{R}^{2}$ (coefficient correlation) was to 1 , the more suitable the model was. Besides, 
experimental methods such as $\mathrm{H}_{2}$-TPR, XPS, TGA and isotope$\mathrm{O}_{2}$ can also be used to determine the reaction kinetics mechanism (Mi et al., 2021).

In most studies, the Mars-van Krevelen model was deemed as the most suitable model for VOCs oxidation. This method is based on the idea that the adsorbed VOCs react with the lattice oxygen of the catalyst, rather than the oxygen in the gas phase. The MVK model assumes that, when the reactant molecules react with the oxygen-rich part of the catalyst, the active components in the reaction can undergo alternating reduction and oxidation reactions. In this case, the oxygen in the reaction process can be chemisorbed or lattice $\mathrm{O}_{2}$. The model assumes that the oxidation of VOCs is divided into two steps. The first step is that the adsorbed VOCs combine with the lattice oxygen on the catalyst surface and are oxidized to $\mathrm{CO}_{2}$ and $\mathrm{H}_{2} \mathrm{O}$. At the same time, oxygen vacancies are generated on the catalyst surface and reduced, causing metal oxides in the catalyst to be reduced as well. In the second step, the reduced metal oxide in the catalyst is oxidized again by external $\mathrm{O}_{2}$ to fill the oxygen vacancy in order to continue the first step reaction (Rodrigues, 2008)

In this review, we summarized the forefront researches of zeolite-based catalysts for VOCs combustion, which provides a reference to design novel VOC oxidation materials.

\section{PREPARATION AND APPLICATION OF ZEOLITES AND ITS COMPOSITE MATERIALS}

The catalytic activity of zeolites catalysts is highly concerned by the acidic sites on the inner pore surface. Single phase zeolites with abundant acidic sites usually perform better in the catalytic process. When the acidity is strong, carbon deposition is likely to occur on the catalyst surface, which affects the catalytic activity (He et al., 2009). ZSM-5 (Zeolite Socony Mobil-5) and SBA-15 (Santa Barbara Amorphous of number 15) have moderate acidity and higher stability, but their catalytic activity is relatively low. However, zeolite catalysts have no advantages over noble metals and transition metal oxides when applied for VOCs oxidation reaction. Therefore, the design of two-phase zeolite materials as catalyst may not have any evident effect on the improvement of catalytic activity. Researchers prefer to use the unique pore structure of molecular sieves to support precious metals for VOCs combustion. In all the previous studies, the main indicator of catalytic activity is temperature at which 50, 90 or $100 \%$ conversion of VOCs have achieved, noted as $\mathrm{T}_{50}, \mathrm{~T}_{90}$ and $\mathrm{T}_{100}$, respectively.

When a noble metal is loaded on the zeolite, the catalytic activity is highly associated with the type, structure and dispersion of this noble metal. Pd/BEA and Pd/FAU zeolites were found to be powerful catalysts for the total oxidation of toluene and propene (Tidahy et al., 2007). Cations could improve the dispersion of noble metal species but decrease the surface area and the micropore volume. Zhang et al. (2018) examined a Pt loaded hierarchical porous MOR (Mordenite) zeolite obtained by a facile acid and alkali post-treatment strategy. The substance exhibited superior performance for toluene catalytic oxidation. In

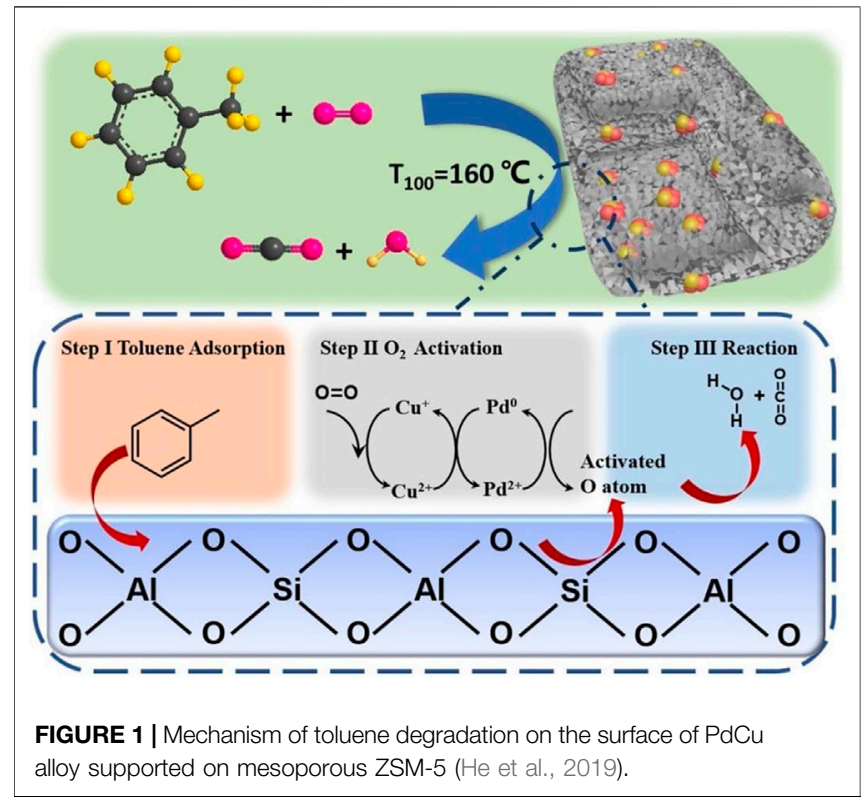

this case, $\mathrm{T}_{90}$ of as-synthesize catalyst over toluene is only $190^{\circ} \mathrm{C}$ $(1,000 \mathrm{ppm}$ toluene in air; WHSV, Weight Hourly Space Velocity $=$ $60,000 \mathrm{ml} /(\mathrm{gH}))$. The neural network model coupled with genetic algorithm was employed to find the optimal transition metal to assist the Ag-zeolite catalyst for VOCs abatement (Izadkhah et al., 2012). It was found that the addition of $\mathrm{Fe}, \mathrm{Ni}$ and $\mathrm{V}$ was more active for ethyl acetate oxidation than in untreated Ag-ZSM-5.

Almost all the transition metal oxides have the potential for VOCs catalytic oxidation. $\mathrm{Cu}, \mathrm{Mn}, \mathrm{Co}$ and $\mathrm{Fe}$ are the common transition metals loaded on zeolite to trigger this process. Soylu et al. (2010) examined these four kinds of oxides supported on natural clinoptilolite-type zeolites to completely degrade toluene. They ordered the activity of fabricated catalysts as: $\mathrm{MnO}_{2}>\mathrm{CuO}$ $>\mathrm{Co}_{3} \mathrm{O}_{4}>\mathrm{Fe}_{2} \mathrm{O}_{3}$ and attributed this phenomenon to the surface Lewis acidity, which played a dominant role in determining the catalytic activity at low temperature.

Researchers have conducted multiple studies on the structural control of oxides or mixed oxides to achieve higher activity. In order to obtain highly uniformed nanastructure, surfactant (e.g., rich-hydroxyl) complexing agents were introduced in the preparation process of materials. Zhang C. et al. (2020) compared the catalytic activity of $\mathrm{Co}_{3} \mathrm{O}_{4}$ nanoparticles onto HZSM-5 with the addition of $\beta$-cyclodextrin, sorbitol and citric acid, respectively. The results showed that the $\mathrm{Co}_{3} \mathrm{O}_{4} / \mathrm{HZSM}-5 / \beta$-cyclodextrin catalyst with increased low-temperature reducibility and more plentiful surface acid sites were more suitable for toluene oxidation. The $\mathrm{T}_{90}$ value for toluene was measured at $288^{\circ} \mathrm{C}(1,000 \mathrm{ppm}$ toluene, $100 \mathrm{ml} / \mathrm{min})$. Liu F. et al. (2019) recently intercalated nanosized $\mathrm{Pt}$ into single-layer sheets of ZSM-5 to form a sandwich-structured catalyst for toluene oxidation. The unique construction ensured a better dispersion and higher thermal stability of $\mathrm{Pt}$. It made $\mathrm{Pt} /$ ZSM-5 displayed higher catalytic activity-around $98 \%$ of toluene could be totally transferred to $\mathrm{CO}_{2}$ and $\mathrm{H}_{2} \mathrm{O}$ at $176^{\circ} \mathrm{C}$ 


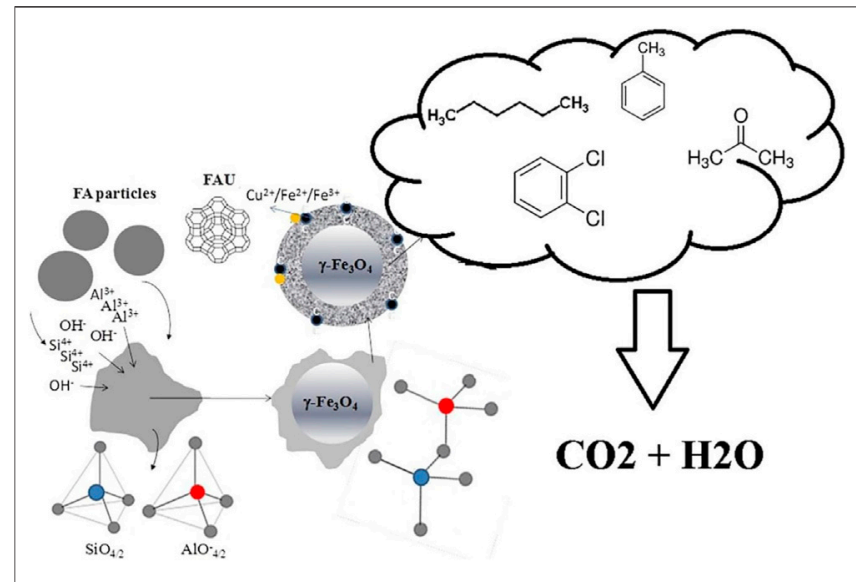

FIGURE 2 | Schematic diagram of zeolite prepared from fly ash and its catalytic performance for VOCs (Boycheva et al., 2019).

$(1,000 \mathrm{ppm}, \mathrm{SV}=60,000 \mathrm{ml} /(\mathrm{gh}))$. The use of carbon material as sacrificial agent is a novel route to build highly dispersed surface structure of catalysts. The loss of carbon black encapsulated by zeolite as a route to form $\mathrm{PdCu}$ alloy supported on mesoporous ZSM-5 zeolite (He J. et al., 2019). The alloying process of $\mathrm{Cu}$ and $\mathrm{Pd}$ resulted in a better activity for toluene oxidation $\left(\mathrm{T}_{90}=152^{\circ} \mathrm{C}, 50 \mathrm{ppm}\right.$ toluene, WHSV $=36000 \mathrm{ml} /(\mathrm{g} \mathrm{h}))$ is shown in Figure 1 .

The combination of perovskite and zeolite was studied by Zang et al. (2019). The structure and morphology of threedimensionally ordered macroporous and nanoparticle $\mathrm{La}_{0.8} \mathrm{Ce}_{0.2} \mathrm{MnO}_{3}$ significantly enhanced the toluene oxidation active associated with the specific surface area of the catalyst. The $\mathrm{T}_{50}$ and $\mathrm{T}_{90}$ value were estimated as $147^{\circ} \mathrm{C}$ and $217^{\circ} \mathrm{C}$. Single atom catalyst is another Frontier of catalyst preparation and application for VOCs combustion (Wang Y. et al., 2020; Zhang et al., 2021). Nozaki et al. (2002) put forward a novel method to prepare a series of single-site catalysts that have isolated iron centers onto SBA-15 by grafting reactions of the $\mathrm{Fe}\left[\mathrm{OSi}(\mathrm{OtBu})_{3}\right]_{3}$ (THF) with SBA-15 in dry hexane.

The high cost of raw material and the complexity of the method are the main constraints for the large-scale use of zeolite. This is why the idea of cheap or waste materialsderived zeolite was brought up. It is worth noting that these kinds of zeolites need to overcome the influence of impurities in order to become active and stable catalysts. Boycheva et al. (2019) used fly ash gathered from thermal power plants to synthesize $\mathrm{Na}-\mathrm{Y}$ zeolite as shown in Figure 2. The catalytic oxidation of $\mathrm{n}$-hexane, acetone, toluene, 1,2 dichlorobenzene was operated on the $\mathrm{Cu}$-modified fly ash-derived zeolite. Cr-loaded $\mathrm{NaY}$ zeolite obtained by bio recovery of chromium from water for ethyl acetate, ethanol and toluene oxidation was reported by Silva et al. (2011). For all VOC tested, the Cr-loaded zeolite performed well and presented satisfactory $\mathrm{CO}_{2}$ selectivity. Authors believed that the presence of $\mathrm{Cr}$ shifted the reaction pathways, leading to enhancement of $\mathrm{CO}_{2}$ selectivity.

\section{ZEOLITE-BASED CATALYSTS FOR CVOCS REMOVAL}

Along with the refinement studies, the control of chlorinated volatile organic compounds (CVOCs) has received a lot of attention from scholars due to their high stability, poor reactivity and high toxicity ( $\mathrm{Li}$ et al., 2020). $\mathrm{CB}\left(\mathrm{C}_{6} \mathrm{H}_{5} \mathrm{Cl}\right)$, DCE $\left(\mathrm{CH}_{2} \mathrm{ClCH}_{2} \mathrm{Cl}\right)$, DCM $\left(\mathrm{CH}_{2} \mathrm{Cl}_{2}\right)$, and TCE $\left(\mathrm{C}_{2} \mathrm{HCl}_{3}\right)$ are the typical CVOCs discharged by industrial sources. The main difficulties in CVOCs catalytic combustion process are the formation of harmful and incomplete combustion products (such as $\mathrm{COCl}_{2}$ ) and the deactivation of catalysts due to coking, carbon deposition and chlorination.

Zeolite materials have a large number of acidic sites. The synergetic effect of Lewis and Bronsted acid sites can effectively improve the chlorobenzene degradation activity and stability. Among them, the introduction of Lewis acid sites promotes the activation of lattice oxygen, improves the redox performance, and is conducive to the oxidation of organic matter and the oxidative removal of adsorbed chlorine. The existence of Bronsted acid site changes the degradation path of chlorobenzene from oxidation to hydrolysis path, promotes the emission of $\mathrm{Cl}$ ions in the form of $\mathrm{HCl}$, fundamentally inhibits the formation of $\mathrm{Cl}_{2}$, and reduces the selectivity of chlorine containing by-products and $\mathrm{Cl}_{2}$ ( $\mathrm{Lv}$ et al., 2021).

Variations of zeolite were designed as active ingredient or carrier of catalysts for the purpose of CVOCs abatement and achieved remarkable results. The catalytic activity of HY zeolite can be improved by adjusting the ratio of silicon to aluminum (Lopez-Fonseca et al., 2003). De-alumination by ammonium hexafluoro silicate treatment increased the number of strong Brønsted sites. DCE could be totally converted at $350^{\circ} \mathrm{C}$ on modified HY zeolite, and the $\mathrm{T}_{50}$ values of DCM and TCE were $345^{\circ} \mathrm{C}$ and $465^{\circ} \mathrm{C}$, respectively $(1,000 \mathrm{ppm}$ CVOCs, GHSV $=$ $\left.15,000 \mathrm{~h}^{-1}\right)$.

To reach better catalytic activity, noble metals such as $\mathrm{Au}, \mathrm{Ag}$, $\mathrm{Pt}$, and $\mathrm{Pb}$ with great properties were also loaded on zeolite for CVOCs removal. Wang Z. et. al. (2020) investigated a bimetallic Pt-Ru supported on HZSM-5 for $\mathrm{CB}\left(\mathrm{C}_{6} \mathrm{H}_{5} \mathrm{Cl}\right)$ catalytic removal. $\mathrm{Pt}_{0.5} \mathrm{Ru}_{0.5} / \mathrm{m}-\mathrm{HZ}$ catalyst could convert $50 \% \mathrm{CB}$ at $234^{\circ} \mathrm{C}$ $(1,000 \mathrm{ppm} \mathrm{CB} /$ dry air, GHSV $=40,000 \mathrm{ml} / \mathrm{gh})$, and the high selectivity for less toxic products $\left(\mathrm{CO}_{2}\right.$ and $\left.\mathrm{HCl}\right)$ and scarce formation of chlorinated byproduct during $50 \mathrm{~h}$ test.

The combination of transition metals combined with zeolites have been widely used to catalytic degrade CVOCs as well. Gonzalez-Prior and co-workers conducted a study of a $\mathrm{Co}_{3} \mathrm{O}_{4} /$ SBA-15 structured catalyst for DCE oxidation (Gonzalez-Prior et al., 2016). They have verified that SBA-15 provided surface $\mathrm{OH}$ groups of SBA- 15 as grafting points in the impregnation process and regulated the dimensions of $\mathrm{Co}_{3} \mathrm{O}_{4}$ nanoparticles by its mesopore structure. Cobalt-loading affected the acidity species and strength of catalysts by adding Lewis acidic sites and reducing the medium-weak Brønsted acidic sites. The $\mathrm{T}_{50}$ value of $40 \mathrm{Co} /$ SBA was $330^{\circ} \mathrm{C}$ and lattice oxygen species in the catalyst were associated with $\mathrm{Cl}-\mathrm{VOC}$ combustion following a Mars-van Krevelen mechanism. (Ce,Cr $)_{\mathrm{x}} \mathrm{O}_{2} / \mathrm{HZSM}-5$ composite materials were prepared by Yang et al. (2017) and performed 
remarkably in DCE degradation. The HZSM-5 provided large amount of acid sites to promote the adsorption and dehydrochlorination of DCE $\left(\mathrm{CH}_{2} \mathrm{ClCH}_{2} \mathrm{Cl}\right)$. After that, the $(\mathrm{Ce}, \mathrm{Cr})_{\mathrm{x}} \mathrm{O}_{2}$ could oxidize the by-product to $\mathrm{CO}_{2}$ quickly and thoroughly. (Ce,Cr) $)_{\mathrm{x}} \mathrm{O}_{2} / \mathrm{HZSM}-5$ after long-term test could be recovered by $400^{\circ} \mathrm{C}$ calcination. Blanch-Raga et al. (2016) fabricated a $\mathrm{Cu}$-exchanged zeolite for TCE oxidation and the $\mathrm{T}_{50} / \mathrm{T}_{90}$ values registered by them were $310^{\circ} \mathrm{C}$ and $360^{\circ} \mathrm{C}$, respectively. They proposed the oxidative properties of $\mathrm{Cu}$ could avoid the formation of coke and protect the acid sites on the surface of the zeolite. The activity and selectivity of assynthesized catalyst in TCE oxidation process was associated with the acidity, redox properties and metal-zeolite interaction. Gołąbek et al. (2019) studied the activity of Ce-BEA for the catalytic oxidation of TCE and the formation mechanism of byproducts. The highly developed mesopore surface area, welldispersed cerium and the amount of high strength Brønsted acid centres and Brønsted sites in the Ce-loaded zeolite catalyst was deemed as the crucial role of activity and selectivity.

\section{ZEOLITE-BASED MONOLITHIC CATALYST EMPLOYED FOR COMBUSTION}

Considering the high pressure drop and difficult separation of powder catalysts, some researchers have started to shift their interest to monolithic catalysts with zeolite components. Zeolites could be consolidated to form pellets or directly wash-coated to other carriers. In the field of VOCs combustion abatement, cordierite is the most common carrier of monolithic catalysts. It has been widely studied and practically applied because of its high strength, low volume density and low coefficient of thermal expansion (Zamaro et al., 2005; Brahmi et al., 2013).

A Pt-MFI zeolite-cordierite foam-structured catalyst was designed and adopted for toluene removal by Ribeiro and coworkers (Ribeiro et al., 2011). The open structure of cordierite foam, uniformly deposited thin layers' catalyst, location and size of $\mathrm{Pt}$ joint acted to perform a good activity $\left(\mathrm{T}_{50} \approx 210^{\circ} \mathrm{C}, 800 \mathrm{ppm}\right.$ toluene in $15 \mathrm{Lh}^{-1}$ air flow). Silva et al. (2008) tested deep oxidation properties of isopropanol on $\mathrm{Cu}$ and $\mathrm{Pt}$ modified MFI zeolite, and achieved a rate of $100 \%$ in the conversions of $\mathrm{CO}_{2}$ at $160^{\circ} \mathrm{C}$ to Pt-MFI catalyst.

Recently, metal carriers such as iron mesh (Xue et al., 2020), stainless steel grid (Louis et al., 2001; Louis et al., 2002), and stainless-steel fiber have been widely reported as the carrier for heat treatment of exhaust gas. Monolithic catalysts with metal basal are identified as an area of future work as a result of its stable, easy shaped and highly efficient heat transfer capabilities. Hydrothermal and chemical vapor deposition (CVD) methods are most favorable for zeolite in-situ decoration on steel fiber.

Zhou et al. (2017) obtained Cu modified catalysts supported on Linde Type A zeolite membrane/paper-like stainless steel fibers (LTA/PSSF) using CVD method. The selected $10 \% \mathrm{Cu} /$ LTA/PSSF catalyst performed well towards acetone oxidation with $\mathrm{T}_{90}$ values at $300^{\circ} \mathrm{C}(1,500 \mathrm{ppm}$ in air $)$. They verified that the CVD method has the potential to obtain highly uniformed $\mathrm{CuO}$ and zeolite nonparticipants onto PSSF basal. Liu G. et al. (2019) synthesized $\mathrm{Cu}$ and $\mathrm{Mn}$ mixed oxides modified beta zeolite coated on PSSF for toluene combustion. The typical truncated bipyramidal shape of beta zeolite on PSSF was obtained via wet lay-up papermaking and sintering process. Then, $\mathrm{Cu}$ and $\mathrm{Mn}$ species were introduced by an incipient wetness impregnating method. Results showed that the catalytic activities over toluene increased as the $\mathrm{Mn}$ content increased as well. The lowest $\mathrm{T}_{90}$ value was $302^{\circ} \mathrm{C}(1,000 \mathrm{ppm}$ toluene in air, $200 \mathrm{ml} / \mathrm{min}$ flow rate) presented by the $\mathrm{CuMn}_{3} /$ Beta/PSSF catalyst.

PSSF based monolithic catalysts have also been investigated in CVOCs removal. Zhang Y. et al. (2020) developed Cr modified ZSM-5 as the active phase onto PSSF membranes and studied the mechanism of TCE combustion $\left(\mathrm{T}_{90}=300^{\circ} \mathrm{C}, 1,500 \mathrm{ppm}\right.$ in air). The Mars-van Krevelen kinetic model could fit well with the TCE degradation data and the reaction activation energy for the surface oxidation/ reduction reaction were $64.57 \mathrm{~kJ} / \mathrm{mol}$ and $122.25 \mathrm{~kJ} / \mathrm{mol}$, respectively.

\section{ZEOLITE-BASED DUAL FUNCTIONAL ADSORBENT/CATALYST SYSTEM FOR VOCS}

VOCs are also emitted from vehicles and in-door cooking. In these cases, the size of treatment facilities is limited to small cage. Therefore, the combination of adsorbents and catalysts is meaningful. Yu et al. (2020) reported a novel ferrisilicate MEL zeolite for cleaning cooking oil fumes with non-methane hydrocarbon. The hydrophobic Si-Fe framework of the catalyst enhanced their hydrophobic feature due to the substitution of $\mathrm{Al}$ by Fe. Various VOCs with different molecular dimensions could be firstly adsorbed onto the catalysts' surface and immediately oxidized by the nanorod-stacking $\mathrm{FeO}_{\mathrm{x}}$. Jang et al. (2021) studied $\mathrm{Cu}$-impregnated BEA zeolite for aromatic adsorption and oxidation applied to control of vehicles' waste gas. Dispersed $\mathrm{Cu}$ ions allowed the preferential adsorption of HCs, and the nanosized $\mathrm{CuO}$ particles on the exterior surface could oxidize HCs starting from $210^{\circ} \mathrm{C}$. The key to achieve high removal efficiency was preferential adsorption of propene under wet conditions.

In large-scale industrial processes, adsorption and catalytic oxidation are the two main stages of VOCs removal. With the aim of shortening the working process and minimizing energy consumption, an integrated material combining adsorption and combustion for industrial use was proposed. Baek et al. (2004) tested the adsorption/desorption and catalytic performance of hydrophobic $\mathrm{Y}$ zeolite materials introduced with different amount of $\mathrm{Ag}, \mathrm{Mn}, \mathrm{Fe}, \mathrm{Co}, \mathrm{Cr}, \mathrm{Cu}, \mathrm{Ni}, \mathrm{Pt}$, and $\mathrm{Pb}$. The $\mathrm{Ag} / \mathrm{HY}$ was selected as the best candidate for the dual functional system. The large adsorption capacity and low desorption temperature in the narrow desorption window guaranteed the continuous adsorption-regeneration cycling. Also, the toluene activity $\left(\mathrm{T}_{100}=290^{\circ} \mathrm{C}, 1,000 \mathrm{ppm}, \mathrm{SV}\right.$ $\left.=6,000 \mathrm{~h}^{-1}\right)$ and $\operatorname{MEK}\left(\mathrm{T}_{100}=290^{\circ} \mathrm{C}, 1,000 \mathrm{ppm}, \mathrm{SV}\right.$ $=6,000 \mathrm{~h}^{-1}$ ) oxidation was enhanced by increasing the $\mathrm{Ag}$ loading. 
Overall, adsorption and catalytic abatement is a new trend in civil or industrial treat of VOCs in which zeolite-based material could give full play to its specialty. Researchers should pay more attention on the economic efficiency and feasibility of this method, and keep studying by-products and the resistance of water vapor and high temperature.

\section{DISCUSSION}

Zeolites have been regarded as a future key components in VOCs combustion catalyst, and many studies have been conducted around this topic. The focus of this work is the optimization of catalyst performance, the reduction of preparation costs and the popularization of its practical application. In recent years, optimization of composition and structure of catalysts have become more diversified and delicately for acquire higher activity. Target pollutants gradually expanded from commonly benzene series VOCs to CVOCs. To meet the need of more practical applications, powder catalysts are assembled or coated to different basal to form monolithic catalysts. Adsorbent/catalyst bi-functional material was reported and attempted to solve the VOCs oxidation in cook, vehicle or industrial situations.

Besides, some new frontiers of zeolite-based catalysts have been recently discovered but few studies about it have been published. For instance, to meet the worldwide demand to

\section{REFERENCES}

Baek, S.-W., Kim, J.-R., and Ihm, S.-K. (2004). Design of dual functional adsorbent/ catalyst system for the control of VOC's by using metal-loaded hydrophobic Y-zeolites. Catal. Today 93-95, 575-581. doi:10.1016/j.cattod.2004.06.107

Beauchet, R., Mijoin, J., Batonneau-Gener, I., and Magnoux, P. (2010). Catalytic oxidation of VOCs on NaX zeolite: Mixture effect with isopropanol and o-xylene. Appl. Catal. B: Environ. 100, 91-96. doi:10.1016/j.apcatb.2010.07.017

Behar, S., Gómez-Mendoza, N.-A., Gómez-García, M.-Á., Świerczyński, D., Quignard, F., and Tanchoux, N. (2015). Study and modelling of kinetics of the oxidation of VOC catalyzed by nanosized $\mathrm{Cu}-\mathrm{Mn}$ spinels prepared via an alginate route. Appl. Catal. A: Gen. 504, 203-210. doi:10.1016/ j.apcata.2014.12.021

Blanch-Raga, N., Palomares, J., Martínez-Triguero, S., and Valencia, A. E. (2016). $\mathrm{Cu}$ and $\mathrm{Co}$ modified beta zeolite catalysts for the trichloroethylene oxidation. Appl. Catal. B: Environ. 187, 90-97.

Boycheva, S., Zgureva, D., Václavíková, M., Kalvachev, Y., Lazarova, H., and Popova, M. (2019). Studies on non-modified and copper-modified coal ash zeolites as heterogeneous catalysts for VOCs oxidation. J. Hazard. Mater 361, 374-382.

Brahmi, R., Agunaou, M., Beaurain, A., Giraudon, J. M., and Lamonier], J. F. (2013). Washcoating of cordierite honeycomb with Ce- $\mathrm{Zr}-\mathrm{Mn}$ mixed oxides for VOC catalytic oxidation. Chem. Eng. J. 223, 536-546.

Chandak, M. V., Lin, Y. S., Ji, W., and Higgins, R. J. (1997). Sorption and diffusion of VOCs in DAY zeolite and silicalite-filled PDMS membranes. J. Membr. Sci. 133, 231-243. doi:10.1016/s0376-7388(97)00082-3

Gonzalez-Prior, J., Gutierrez-Ortiz, J. I., Lopez-Fonseca, R., Busca, G., Finocchio, E., and De Rivas, B. (2016). Oxidation of chlorinated alkanes over Co3O4/SBA15 catalysts. Structural characterization and reaction mechanism. Catal. Sci. Technol. 6, 5618-5630. doi:10.1039/c6cy00321d

Gołąbek, K., Palomares, A. E., Martínez-Triguero, J., Tarach, K. A., and GóraMarek, K. (2019). Ce-modified zeolite BEA catalysts for the trichloroethylene oxidation. The role of the different and necessary active sites. Appl. Catal. B: Environ. 259, 118022. reduce greenhouse gas emission and achieving carbon neutrality, the oxidation of VOCs and the adsorption of $\mathrm{CO}_{2}$ emitted after VOCs catalytic combustion could be successively achieved by zeolite (Mp et al., 2020). The mixture effect with different VOCs under oxidation was studied by Beauchet et al. (2010) and an inhibiting effect of the o-xylene on the isopropanol oxidation was observed. This is because the adsorbed aromatic VOCs near the apertures of the $\mathrm{NaX}$ supercages limit the access of isopropanol to the basic active sites.

We need to widen the studies around the mechanism of VOCs oxidation induced by zeolites, and explore the ways to deal with the water and high temperature conditions that may be encountered in practical applications. Besides, the simultaneous removal of different VOCs, VOCs/ $\mathrm{NO}_{\mathrm{x}}, \mathrm{VOCs} /$ $\mathrm{CO}_{2}$ could be a more realistic problem to solve.

\section{AUTHOR CONTRIBUTIONS}

TX and LY proposed and wrote the manuscript.

\section{FUNDING}

This work was supported by the National key research and development program of China (2017YFC0213002).

He, C., Cheng, J., Zhang, X., Douthwaite, M., Pattisson, S., and Hao, Z. (2019a) Recent advances in the catalytic oxidation of volatile organic compounds: a review based on pollutant sorts and sources. Chem. Rev. 119, 4471-4568. doi:10.1021/acs.chemrev.8b00408

He, C., Li, J., Cheng, J., Li, L., Li, P., Hao, Z., et al. (2009). Comparative studies on porous material-supported $\mathrm{Pd}$ catalysts for catalytic oxidation of benzene, toluene, and ethyl acetate. Ind. Eng. Chem. Res. 48 (15), 6930-6936. doi:10.1021/ie900412c

He, J., Chen, D., Li, N., Xu, Q., and Lu, J. (2019b). Controlled fabrication of mesoporous ZSM-5 zeolite-supported $\mathrm{PdCu}$ alloy nanoparticles for complete oxidation of toluene. Appl. Catal. B: Environ. 265, 118560.

Izadkhah, B., Nabavi, S. R., Niaei, A., Salari, D., Mahmuodi Badiki, T., and Çaylak, N. (2012). Design and optimization of Bi-metallic Ag-ZSM5 catalysts for catalytic oxidation of volatile organic compounds. J. Ind. Eng. Chem. 18, 2083-2091. doi:10.1016/j.jiec.2012.06.002

Jang, E., Choi, L., Kim, J., Jeong, Y., Baik, H., Kang, C. Y., et al. (2021). A copperimpregnated BEA zeolite for adsorption and oxidation of aromatic species during vehicle cold starts. Appl. Catal. B: Environ. 287, 119951. doi:10.1016/ j.apcatb.2021.119951

Kim, K.-J., and Ahn, H.-G. (2012). The effect of pore structure of zeolite on the adsorption of VOCs and their desorption properties by microwave heating. Microporous Mesoporous Mater. 152, 78-83. doi:10.1016/ j.micromeso.2011.11.051

Li, C., Zhao, Y., Song, H., and Li, H. (2020). A review on recent advances in catalytic combustion of chlorinated volatile organic compounds. J. Chem. Tech. Biotechnol., 95. doi:10.1002/jctb.6308

Liotta, L. F. (2010). Catalytic oxidation of volatile organic compounds on supported noble metals. Appl. Catal. B: Environ. 100, 403-412. doi:10.1016/ j.apcatb.2010.08.023

Liu, F., Zhang, H., Yan, Y., and Wang, T. (2019). Preparation and characterization of $\mathrm{Cu}$ and $\mathrm{Mn}$ modified Beta zeolite membrane catalysts for toluene combustion. Mater. Chem. Phys. 241, 122322.

Liu, G., Tian, Y., Zhang, B., Wang, L., and Zhang, X. (2019). Catalytic combustion of VOC on sandwich-structured Pt@ZSM-5 nanosheets prepared by 
controllable intercalation. J. Hazard. Mater. 367, 568-576. doi:10.1016/ j.jhazmat.2019.01.014

López-Fonseca, R., de Rivas, B., Gutiérrez-Ortiz, J. I., Aranzabal, A., and GonzálezVelasco, J. R. (2003). Enhanced activity of zeolites by chemical dealumination for chlorinated VOC abatement. Appl. Catal. B: Environ. 41, 31-42. doi:10.1016/s0926-3373(02)00199-6

Louis, B., Kiwi-Minsker, L., Reuse, P., and Renken, A. (2001). ZSM-5 coatings on stainless steel grids in one-step benzene hydroxylation to phenol by $\mathrm{N} 2 \mathrm{O}$ : reaction kinetics study. Ind. Eng. Chem. Res. 40, 1454-1459. doi:10.1021/ ie0007441

Louis, B., Subrahmanyam, C., Kiwi-Minsker, L., Viswanathan, B., Buffat, P. A., and Renken, A. (2002). Synthesis and characterization of MCM-41 coatings on stainless steel grids. Catal. Commun. 3, 159-163. doi:10.1016/s1566-7367(02)00074-2

Lv, X., Cai, S., Chen, J., Jiang, M., Chen, J., and Jia, H. (2021). Tuning the degradation activity and pathways of chlorinated organic pollutants over $\mathrm{CeO}_{2}$ catalyst with acid sites: synergistic effect of Lewis and Brønsted acid sites. Catal. Sci. Tech. 2021, 11.

Megías-Sayago, C., Bingre, R., Huang, L., Lutzweiler, G., Wang, Q., and Louis, B. (2019). CO2 Adsorption Capacities in Zeolites and Layered Double Hydroxide Materials. Front. Chem. 7, 551-560. doi:10.3389/ fchem.2019.00551

Mi, R., Li, D., Hu, Z., and Yang, R. T. (2021). Morphology effects of $\mathrm{CeO} 2$ nanomaterials on the catalytic combustion of toluene: A combined kinetics and diffuse reflectance infrared fourier transform spectroscopy study. ACS Catal. 11, 7876-7889. doi:10.1021/acscatal.1c01981

Mp, A., Sb, B., Hl, A., Dz, C., Kl, D., and Gs, E. (2020). VOC oxidation and CO2 adsorption on dual adsorption/catalytic system based on fly ash zeolites. Catal. Today 357, 518-525.

Nozaki, C., Lugmair, C. G., Bell, A. T., and Tilley, T. D. (2002). Synthesis, characterization, and catalytic performance of single-site iron(III) centers on the surface of SBA-15 silica. J. Am. Chem. Soc. 124, 13194-13203. doi:10.1021/ja020388t

Ribeiro, F., Silva, J. M., Silva, E., Vaz, M. F., and Oliveira, F. A. C. (2011). Catalytic combustion of toluene on Pt zeolite coated cordierite foams. Catal. Today 176, 93-96. doi:10.1016/j.cattod.2011.02.007

Rodrigues, A. C. C. (2008). Gas-phase toluene oxidation over platinum-containing mixed oxides. React. Kinet Catal. Lett. 93 (2), 343-350. doi:10.1007/s11144008-5258-x

Silva, B., Figueiredo, H., Santos, V. P., Pereira, M. F. R., Figueiredo, J. L., Lewandowska, A. E., et al. (2011). Reutilization of $\mathrm{Cr}-\mathrm{Y}$ zeolite obtained by biosorption in the catalytic oxidation of volatile organic compounds. J. Hazard. Mater. 192, 545-553. doi:10.1016/j.jhazmat.2011.05.056

Silva, E., Catalão, R., Silva, J., Vaz, F., Oliveira, F., Ribeiro, F. R., et al. (2008). Zeolite-coated ceramic foams for VOCs removal. Stud. Surf. Sci. Catal. 174, 1195-1198. doi:10.1016/s0167-2991(08)80101-2

Soylu, G. S. P., Özçelik, Z., and Boz, I (2010). Total oxidation of toluene over metal oxides supported on a natural clinoptilolite-type zeolite. Chem. Eng. J. 162, 380-387.

Tidahy, H. L., Siffert, S., Lamonier, J.-F., Cousin, R., Zhilinskaya, E. A., Aboukaïs, A., et al. (2007). Influence of the exchanged cation in Pd/BEA and Pd/FAU zeolites for catalytic oxidation of VOCs. Appl. Catal. B: Environ. 70, 377-383. doi:10.1016/j.apcatb.2006.02.027

Wang, Y., Chen, Y., Zhang, L., Wang, G., Deng, W., and Guo, L. (2020). Total catalytic oxidation of chlorinated aromatics over bimetallic Pt-Ru supported on hierarchical HZSM-5 zeolite. Microporous Mesoporous Mater. 308, 110538. doi:10.1016/j.micromeso.2020.110538
Wang, Z., Yang, H., Liu, R., Xie, S., Liu, Y., Dai, H., et al. (2020). Probing toluene catalytic removal mechanism over supported Pt nano- and single-atomcatalyst. J. Hazard. Mater. 392, 122258. doi:10.1016/j.jhazmat.2020.122258

Xue, T., Li, R., Gao, Y., and Wang, Q. (2020). Iron mesh-supported vertically aligned Co-Fe layered double oxide as a novel monolithic catalyst for catalytic oxidation of toluene. Chem. Eng. J. 384, 123284. doi:10.1016/j.cej.2019.123284

Yang, P., Zuo, S., and Zhou, R. (2017). Synergistic catalytic effect of (Ce,Cr) x O 2 and HZSM-5 for elimination of chlorinated organic pollutants. Chem. Eng. J. 323, 160-170. doi:10.1016/j.cej.2017.04.002

Yu, Q., Feng, Y., Tang, X., Yi, H., Zhao, S., Gao, F., et al. (2020). A novel ferrisilicate MEL zeolite with bi-functional adsorption/catalytic oxidation properties for non-methane hydrocarbon removal from cooking oil fumes. Microporous Mesoporous Mater. 309, 110509. doi:10.1016/j.micromeso.2020.110509

Zamaro, J., Ulla, M., and Miró, E. (2005). Zeolite washcoating onto cordierite honeycomb reactors for environmental applications. Chem. Eng. J. 106, 25-33. doi:10.1016/j.cej.2004.11.003

Zang, M., Zhao, C., Wang, Y., Liu, X., Cheng, Y., and Chen, S. (2019). Low temperature catalytic combustion of toluene over three-dimensionally ordered La0.8Ce0.2MnO3/cordierite catalysts. Appl. Surf. Sci. 483, 355-362. doi:10.1016/j.apsusc.2019.03.320

Zhang, C., Wang, Y., Li, G., Chen, L., Zhang, Q., Wang, D., et al. (2020). Tuning smaller $\mathrm{Co} 3 \mathrm{O} 4$ nanoparticles onto HZSM-5 zeolite via complexing agents for boosting toluene oxidation performance. Appl. Surf. Sci. 532, 147320. doi:10.1016/j.apsusc.2020.147320

Zhang, H., Zheng, X., Xu, T., and Zhang, P. (2021). Atomically dispersed Y or La on birnessite-Type $\mathrm{MnO} 2$ for the catalytic decomposition of low-concentration toluene at room temperature. ACS Appl. Mater. Inter. 13, 17532-17542. doi:10.1021/acsami.1c01433

Zhang, J., Rao, C., Peng, H., Peng, C., Zhang, L., Xu, X., et al. (2018). Enhanced toluene combustion performance over Pt loaded hierarchical porous MOR zeolite. Chem. Eng. J. 334, 10-18. doi:10.1016/j.cej.2017.10.017

Zhang, Y., Zhang, H., and Yan, Y. (2020). Kinetic studies of trichloroethylene catalytic combustion over Cr/ZSM-5/PSSF composite. Sep. Purif. Tech. 251, 116827. doi:10.1016/j.seppur.2020.116827

Zhou, C., Zhang, H., Yan, Y., and Zhang, X. (2017). Catalytic combustion of acetone over Cu/LTA zeolite membrane coated on stainless steel fibers by chemical vapor deposition. Microporous Mesoporous Mater. 248, 139-148. doi:10.1016/j.micromeso.2017.04.020

Conflict of Interest: The authors declare that the research was conducted in the absence of any commercial or financial relationships that could be construed as a potential conflict of interest.

Publisher's Note: All claims expressed in this article are solely those of the authors and do not necessarily represent those of their affiliated organizations, or those of the publisher, the editors and the reviewers. Any product that may be evaluated in this article, or claim that may be made by its manufacturer, is not guaranteed or endorsed by the publisher.

Copyright $\odot 2021$ Xue and Yang. This is an open-access article distributed under the terms of the Creative Commons Attribution License (CC BY). The use, distribution or reproduction in other forums is permitted, provided the original author $(s)$ and the copyright owner(s) are credited and that the original publication in this journal is cited, in accordance with accepted academic practice. No use, distribution or reproduction is permitted which does not comply with these terms. 